\title{
20. PALEOMAGNETIC CONSTRAINTS ON THE AGE OF LOWER CRETACEOUS CORES FROM DEEP SEA DRILLING PROJECT SITE 535, SOUTHEASTERN GULF OF MEXICO ${ }^{1}$
}

\author{
Margaret M. Testarmata, The University of Texas at Austin, Institute for Geophysics, Austin, Texas
}

\begin{abstract}
Cretaceous deep-water limestones from Site 535 have low intensities of magnetization, but stable inclinations (37.8 \pm 7.3 ) that can readily be isolated after demagnetization to 25 oersteds. The magnetic stratigraphy of the studied portion (sub-bottom depth $354.0-515.5 \mathrm{~m}$ ) shows only two reverse samples, which may be the result of misorientation. The micropaleontological dating of this section as Albian to Hauterivian had implied that several reversals from the $\mathrm{M}$ anomaly sequence would be observed. The presence of only normally magnetized samples suggests instead that the studied portion is completely within the Cretaceous long normal zone (Santonian to Aptian). Thus the paleomagnetic data indicate that the micropaleontological dates are too old, a contention supported by postcruise ammonite studies.
\end{abstract}

\section{INTRODUCTION}

The Glomar Challenger drilled 6 sites in the southeastern Gulf of Mexico in the winter of 1980-1981 during Leg 77 (Fig. 1A). Two of these sites, 535 and 540, were stratigraphically offset so that a fairly complete section could be obtained from above the inferred midCretaceous unconformity (MCU) through Unconformity 2 (Fig. 1B). At the deeper site, Site $535,559.5 \mathrm{~m}$ of Cretaceous deep-water limestones were penetrated, with recovery averaging $71 \%$. Shipboard paleontologists dated these limestones as ranging from Albian to Late Berriasian with hiatus in the Aptian and Barremian.

Paleomagnetic measurements were made on part of this core with the objective of correlating the results with the marine magnetic time scale and further refining the dates provided by broad-ranging fauna. Four hundred nine vertically oriented minicores were collected at $0.5-0.8 \mathrm{~m}$ spacing from a $361 \mathrm{~m}$ portion (sub-bottom depth 154.5-515.5 m) dated as Albian to Hauterivian. This time period includes the early part of the Cretaceous long normal period and several reversals of the underlying $\mathrm{M}$ anomaly sequence. In addition, 20 samples were collected near the base of the core (sub-bottom depths $673.5-696 \mathrm{~m}$ ), which was dated as early Valanginian to late Berriasian. The magnetic directions of these samples could be useful in discerning any Early Cretaceous plate motion that occurred in the southeastern Gulf of Mexico.

\section{METHODS AND MEASUREMENTS}

\section{NRM Measurements}

Because very low intensities of magnetization $(4.9 \times$ $10^{-9}$ to $2.9 \times 10^{-7} \mathrm{emu} / \mathrm{cm}^{3}$ ) prevented shipboard measurements, all samples were measured postcruise with a cryogenic magnetometer at the University of Texas Institute for Geophysics. Prior to and during the measure-

\footnotetext{
${ }^{1}$ Buffler, R. T., Schlager, W., et al., Init. Repts. DSDP, 77: Washington (U.S. Govt. Printing Office).
}
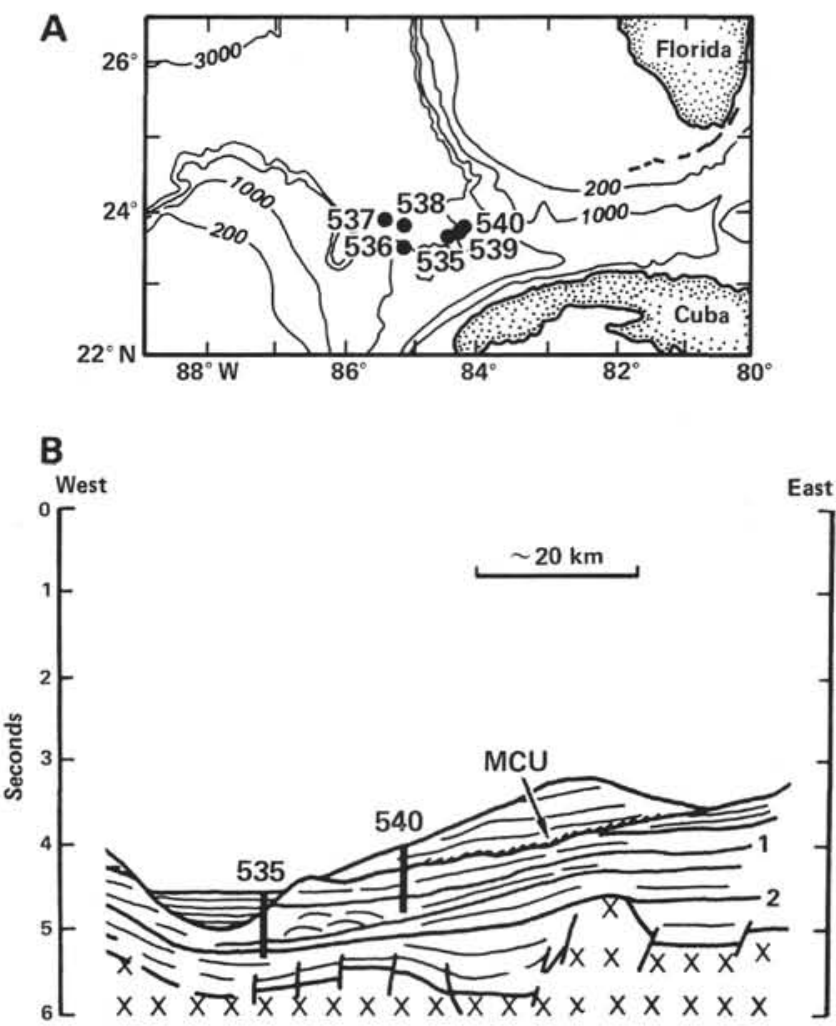

Figure 1. A. Location of the six DSDP sites drilled on Leg 77 in the southeastern Gulf of Mexico. B. Schematic seismic section shows stratigraphic relationship between Sites 535 and 540 and the major unconformities, mid-Cretaceous unconformity (MCU), and Unconformities 1 and 2 .

ments, samples were stored in a magnetically shielded room whose ambient field was approximately 100 gammas. Fields in the magnetometer and demagnetizing equipment were less than 5 gammas.

The 361-m section was subdivided into two parts, Cores 18 through 38 (sub-bottom depth $154.5-354.0 \mathrm{~m}$ ) and Cores 39 through 56 (sub-bottom depth 354.0-515.5 m). Although the mean inclinations of the natural remanent magnetization (NRM) agree for the two portions, the dis- 
tribution of NRM inclinations and intensities differs significantly (Fig. 2). The upper section has a much lower standard deviation than the lower section with respect to both parameters. One can observe in Figures 3 and 4 that the actual changes do not occur at a sub-bottom depth of $354 \mathrm{~m}$, but rather at approximately $310 \mathrm{~m}$ where the intensity range increases and at $400 \mathrm{~m}$ where the intensities decrease significantly and the inclination range widens. The $400 \mathrm{~m}$ discontinuity corresponds to a significant Aptian unconformity marked by lithologic changes. Ammonite studies (Young, this volume) indicate that the Cretaceous sedimentary rocks above this depth have been reworked.

The 20 samples from the base of the core have very low NRM intensities and widely scattered NRM inclinations (Fig. 5). The scatter seems to be largely the result of a viscosity experiment conducted with these samples. Those samples indicated by $\boldsymbol{\Delta}$ in Figure 5 were stored in the Earth's field prior to NRM measurement, while the others $(\bullet)$ were stored in a field-free environment for several months. Those stored in the low field space show inclinations close to the value of $41^{\circ}$ which was observed for the overlying samples (see Fig. 2). The scatter among those stored in the Earth's field suggests that these samples have acquired a viscous remanent magnetization, and it points out the need for a field-free space on the Glomar Challenger where such samples can be stored and measured. Although alternating field demagnetization (AF) was attempted on all 20 samples, their extremely low intensities made it difficult to isolate a stable remanence. Therefore, no information about Early Cretaceous plate motion in the Gulf of Mexico could be extracted.

\section{Demagnetization}

Because of lack of funding, only the lower portion (Cores 39 through 56) of the long section was demagnetized. This part was deemed more important because it ranged in age from Albian to Hauterivian and therefore should have recorded the transition from the frequent reversals of the $\mathrm{M}$ anomaly sequence to the Cretaceous long normal period (see Fig. 6). The upper section, entirely within the Albian, would have presented an excellent opportunity to investigate short reversal events within the Cretaceous long normal zone (VandenBerg and Wonders, 1980; Lowrie et al., 1980) but would not have offered the reversals necessary to correlate the section with the marine magnetic time scale.

One hundred eighty samples were demagnetized at 3 to 6 steps between 25 and 300 oersteds (Oe) to isolate the stable magnetization. For all but 4 samples, a stable component was readily isolated, usually after demagnetization to $25 \mathrm{Oe}$. The consistency of the directions of
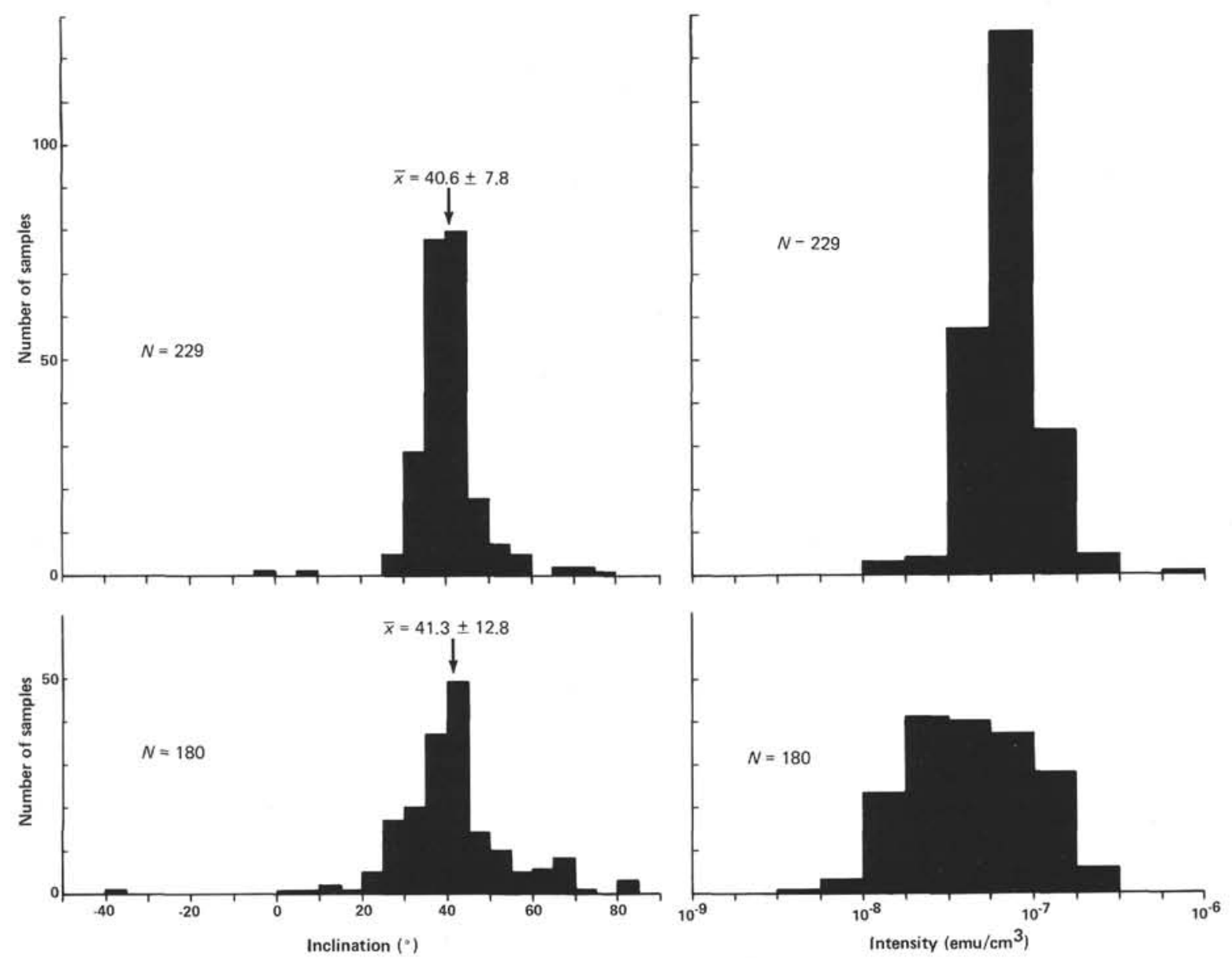

Figure 2. Distribution of NRM inclinations and NRM intensities for Cores 18 through 38 (upper) and Cores 39 through 56 (lower). $\bar{x}$ represents mean value with its standard deviation. 


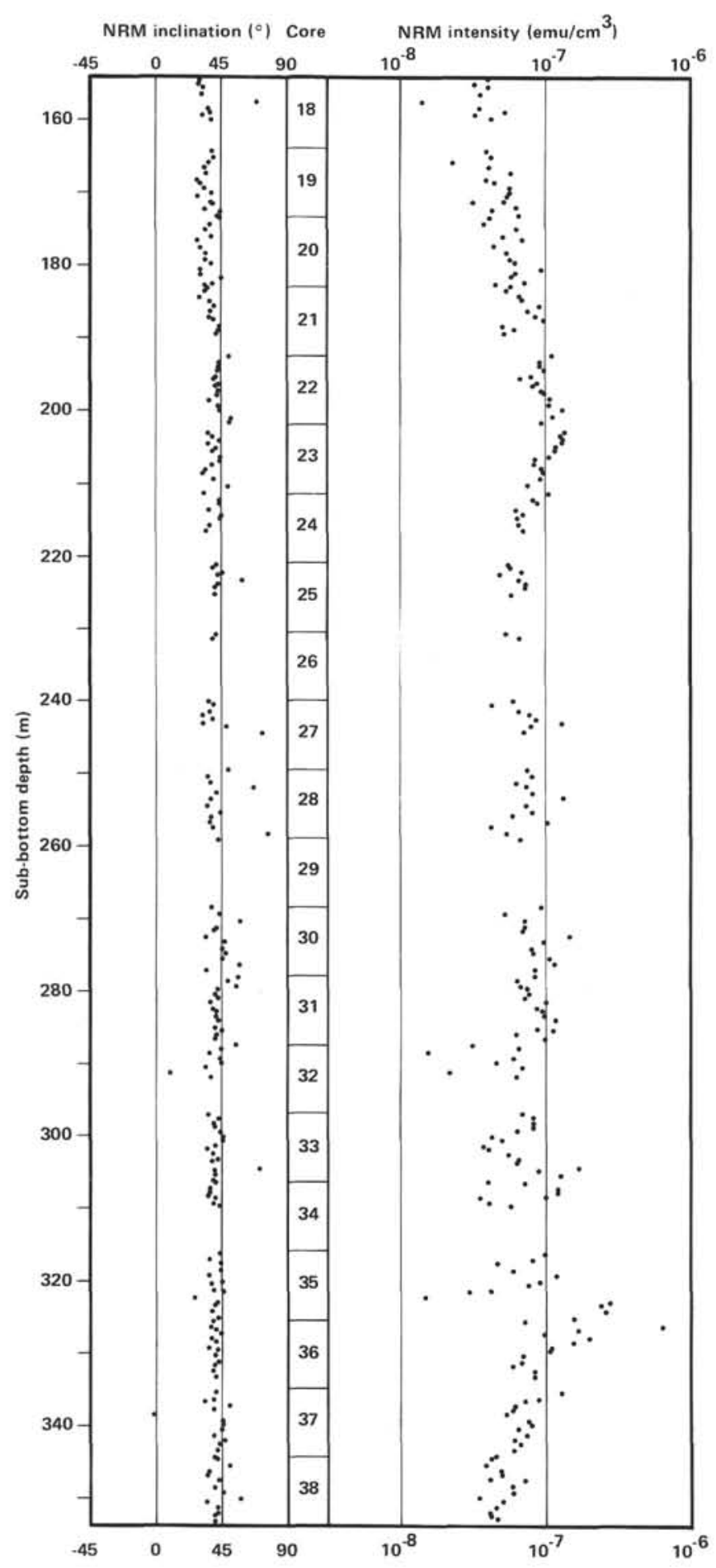

Figure 3. NRM inclinations and NRM intensities as a function of depth for all samples from Cores 18 through 38 .

magnetization upon further demagnetization (Fig. 7) attests to the high quality of the data, especially when one considers the low intensities. Figure 8 shows that demagnetization has tightened the cluster of inclinations and has lowered the mean to $38^{\circ}$ from the NRM value of $41^{\circ}$.

\section{Magnetic Mineralogy}

Before the data can be used for dating the core, it must be ascertained that the stable magnetization was

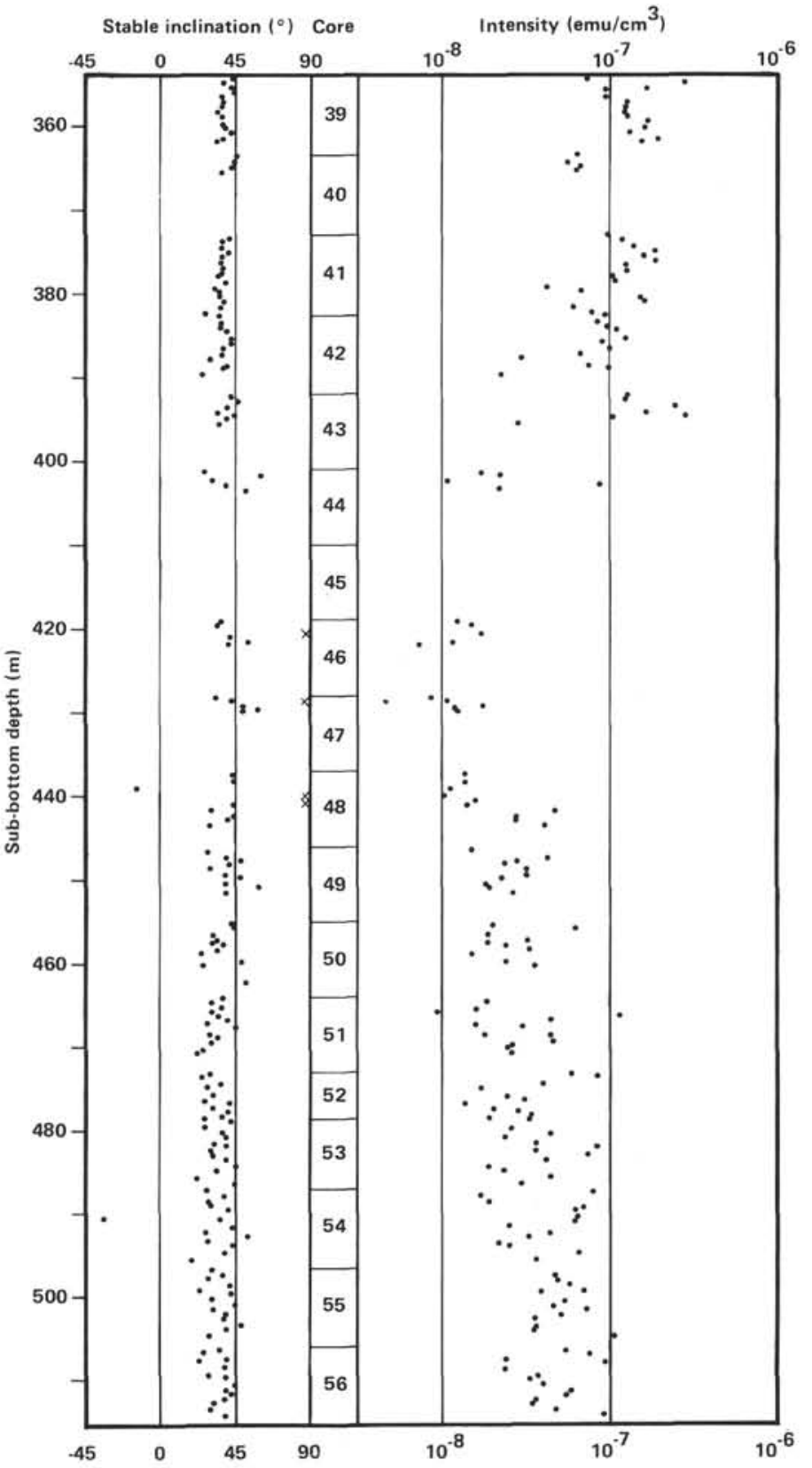

Figure 4. Stable inclinations, observed after demagnetization, and NRM intensities for samples from Cores 39 through 56 . X denotes samples for which no stable inclination was observed.

acquired during or soon after deposition. Several rock magnetic experiments imply that the stable remanence is carried by fine-grained magnetite. Stepwise thermal demagnetization to $400^{\circ} \mathrm{C}$ was conducted on 8 samples (sub-bottom depths $326-350 \mathrm{~m}$ ) which had not been subjected to AF demagnetization. In all cases, the intensity of magnetization decreases gradually with temperature (Fig. 9). The absence of a marked change near $320^{\circ} \mathrm{C}$ precludes pyrrhotite as a significant contributor to the remanence. In a second experiment, 7 representative samples, which had already been AF demagnetized, were given an isothermal remanent magnetization (IRM) in fields up to $5 \mathrm{kOe}$. The acquisition curve (Fig. 10) is typical for fine-grained (i.e., single domain) magnetite. 


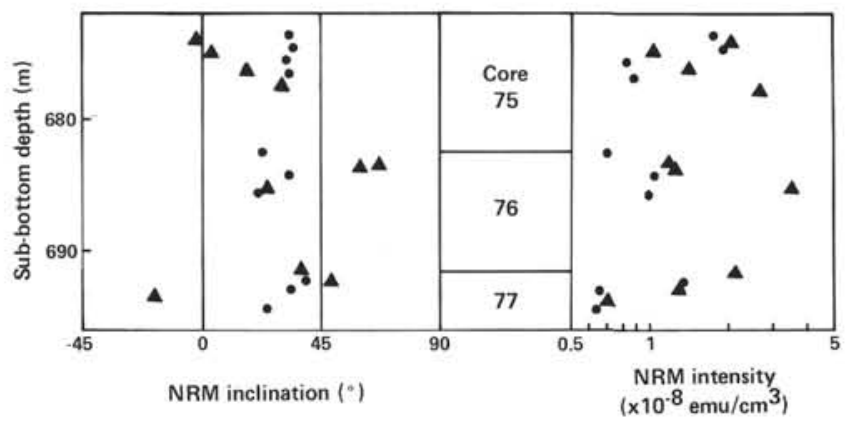

Figure 5. NRM inclinations and NRM intensities for twenty samples from the bottom of Site 535. $\mathbf{\Delta}$ indicates samples stored in the Earth's field and $\bullet$, samples stored in a field-free space for several months prior to NRM measurement.

Subsequent thermal demagnetization to $600^{\circ} \mathrm{C}$ confirmed the dominant role of magnetite (Curie temperature of $577^{\circ} \mathrm{C}$ ) when the IRM diminished to zero between $550^{\circ}$ and $600^{\circ} \mathrm{C}$ (Fig. 10).

To further investigate the magnetic mineral content, representative samples were analyzed by semi-quantitive elemental analysis using a scanning electron microscope by David Watkins (Florida State University). No magnetite was found, which is not surprising because the magnetic experiments imply small grain sizes as well as low concentrations. The only two iron phases observed were pyrite $\left(\mathrm{FeS}_{2}\right)$ and pyrrhotite $\left(\mathrm{FeS}_{1+\mathrm{x}}\right)$, commonly present in marine sediments. Pyrite, a nonmagnetic mineral, is found in spherical clusters of tetrahedral crystals. Pyrrhotite occurs as formless lumps with a composition $\mathrm{FeS}_{1.1-1.3}$. Its lack of form and the absence of interpenetration with adjacent grains suggests that the pyrrhotite is detrital or formed shortly after deposition.

These experiments and observations imply that the stable remanence of these rocks is carried mainly, if not exclusively, by single domain magnetite. The possibility that the stable magnetization is a viscous remanent magnetization (VRM) acquired during the current polarity epoch, is highly unlikely because most single domain grains have very much longer relaxation times. Mild heating $\left(\sim 200^{\circ} \mathrm{C}\right)$ will erase readily such a VRM (Dunlop, 1973), yet no significant change in magnetization was recognized during thermal demagnetization. Because magnetite is, except under very special conditions, of detrital origin, the stable magnetization was acquired during or soon after deposition.

\section{RESULTS}

The stable inclinations are plotted stratigraphically in Figure 4 . The resulting reversal stratigraphy is quite surprising: only two reversely magnetized samples among 174 normally magnetized samples. The two reverse samples are not grouped stratigraphically, and could possibly be the result of orientation errors, rather than representative of reverse polarity events.

Additional minicores were collected at closer spacing $(\sim 10 \mathrm{~cm})$ around one of these samples (535-54-3, 20 $\mathrm{cm})$ to check the validity of the negative inclination. As shown in Figure 11, all surrounding samples are of positive inclination, which suggests that Sample 535-54-3,

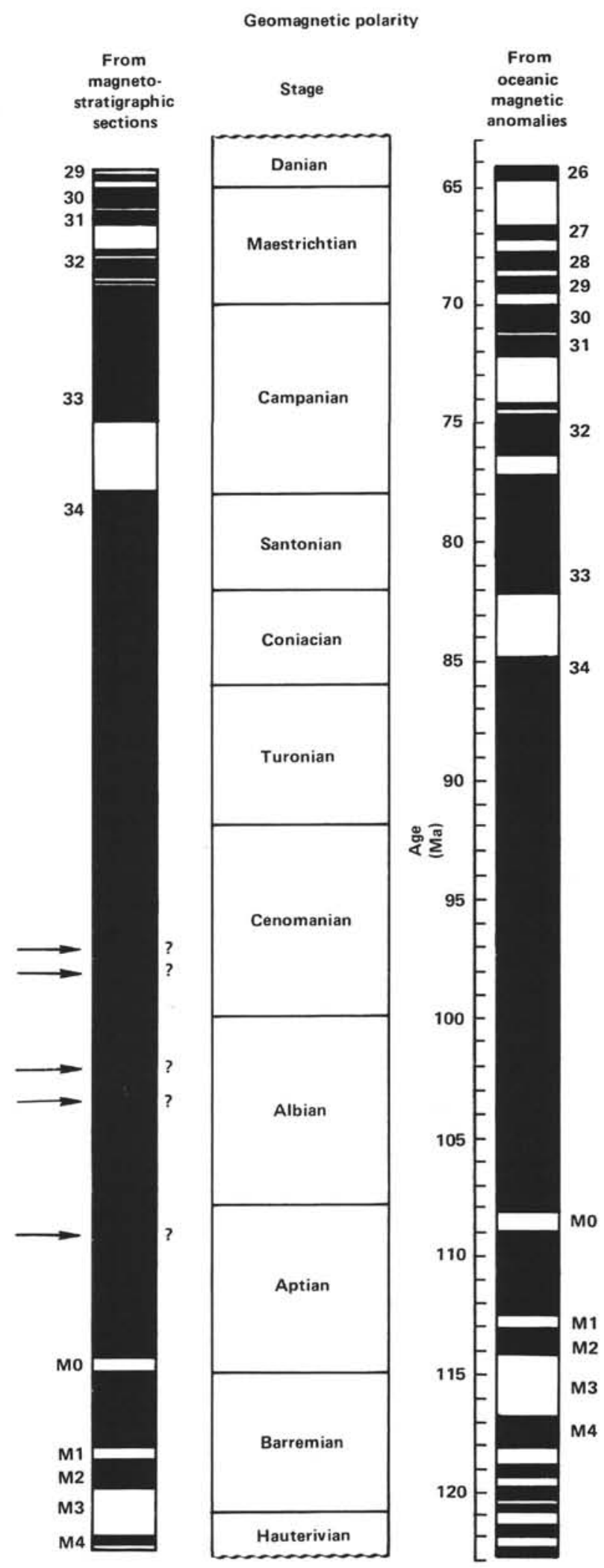

Figure 6. Geomagnetic polarity sequence for the Cretaceous as derived from magnetostratigraphic sections and ocean magnetic anomalies (after Lowrie et al., 1980). Arrows and question marks indicate the position of reported reversals within the Cretaceous long normal period. 


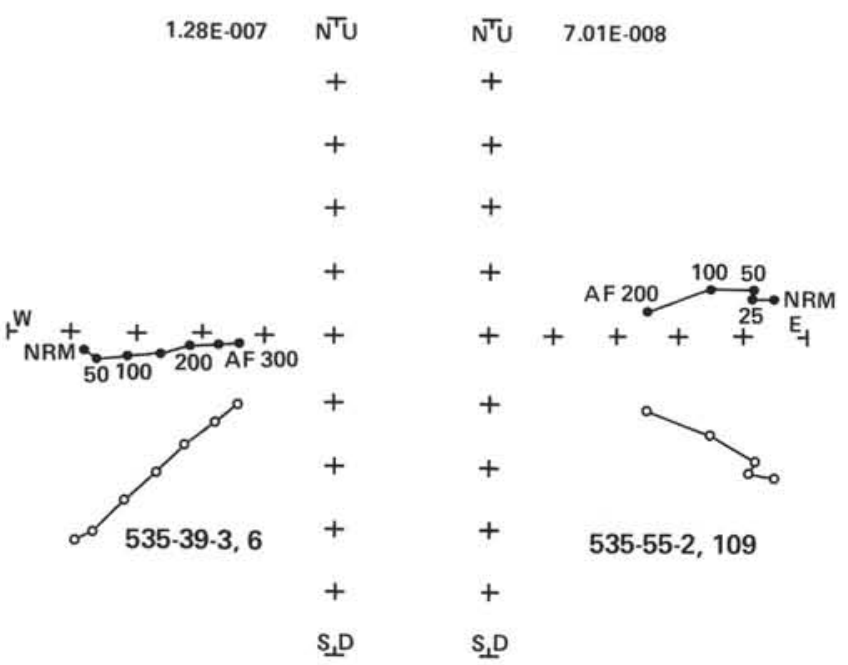

Figure 7. Exemplary orthogonal vector diagrams. Closed circles represent north versus east component; open circles indicate up versus east component. Note that the stable component is isolated after demagnetization to 25 or $50 \mathrm{Oe}$.

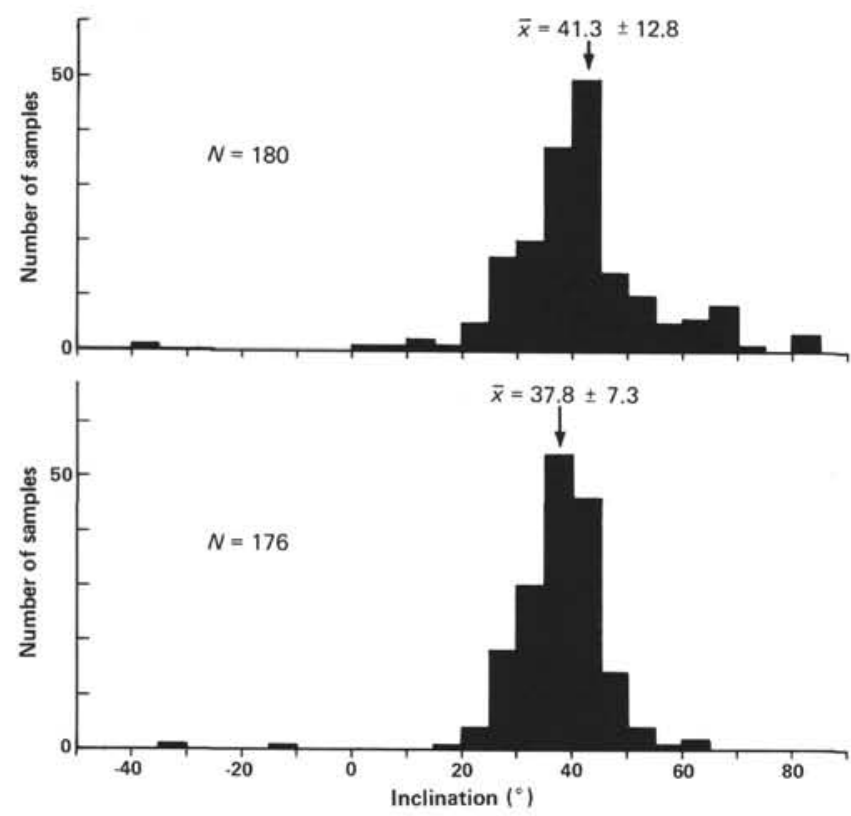

Figure 8. Distribution of inclinations for Cores 39 through 56. Upper histogram shows NRM inclinations; lower plot, stable inclinations. $\bar{x}$ represents mean inclination with its standard deviation.

$20 \mathrm{~cm}$ is misoriented. Without further documentation of either reverse zone, it will be necessary to regard the two samples with negative inclinations as the probable result of misorientation, rather than as records of geomagnetic events.

\section{DISCUSSION}

All minicores are of normal polarity, suggesting that the measured interval is entirely within the Cretaceous long normal period. Yet according to the paleontological dates, the rocks below 400-m sub-bottom depth are Aptian and older, and should have recorded several reversals from the $M$ anomaly sequence (see Fig. 12). There are several possible explanations for the discrepancy: (1)

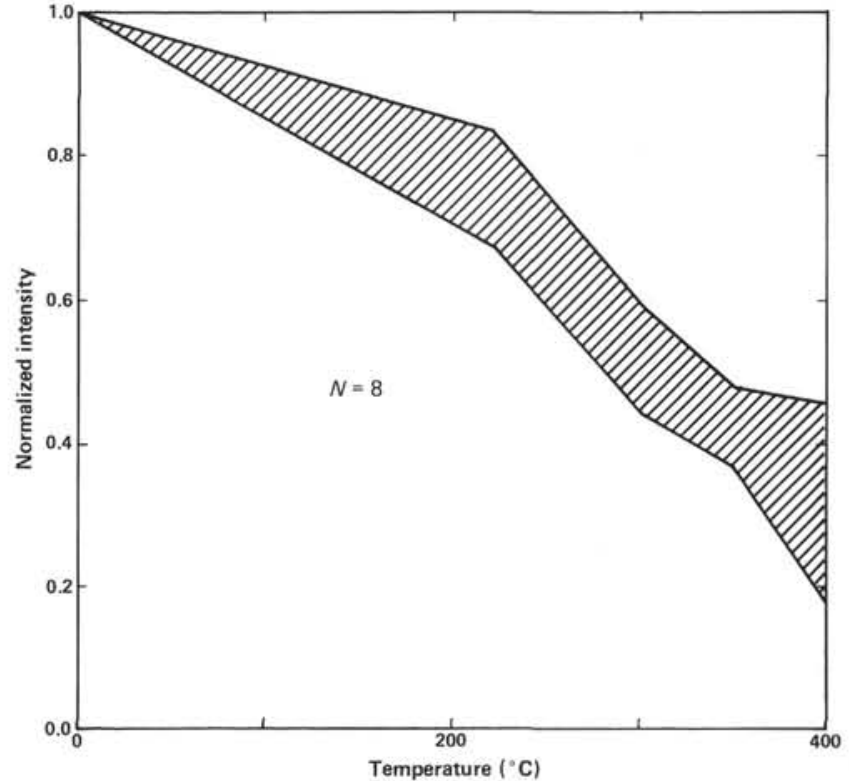

Figure 9. Normalized intensity as a function of temperature for eight samples heated stepwise to $220,300,350$, and $400^{\circ} \mathrm{C}$. Hachured envelope represents the range of the eight samples.

due to a fortuitous deposition rate and sampling frequency, we did not observe the reverse zones in the M anomaly sequence because of a variable deposition rate and sampling frequency; (2) the core has been remagnetized during a normal epoch; (3) the entire measured interval is within the Cretaceous long normal zone and the paleontological dating is erroneous.

The first alternative, that the reversed zones were simply not recorded or detected, seems unlikely when examined in detail. Cores 47 through 50 are from the Lithraphidites bollii nannofossil Zone (site chapter, Site 535 , this volume). Paleomagnetic studies of marine limestones in Europe have shown that this zone corresponds to a largely reversely magnetized interval consisting of reversals M2-M5 (Channell et al., 1979). Using biostratigraphy for correlation, Figure 12 compares Site 535 magnetics with that observed in European limestones. All but one (misoriented?) of the 27 samples from the $L$. bollii zone of Cores 47 through 50 are of normal polarity. It seems unreasonable to explain the paucity of reversed samples by an extremely high deposition rate during the shorter, less frequent normal intervals. Likewise, fortuitous sampling of the core seems an improbable explanation. The lack of reversals in Cores 51 through 56 (Calcicalathina oblongata) is more understandable because only two short reversed zones are expected in the upper portion of the $C$. oblongata zone. The reversed sample in Core 54, if not the result of misorientation, could be a record of one of these.

The second possible explanation is remagnetization. Unfortunately, the time of magnetization or possible remagnetization cannot be constrained by the measured inclinations. According to Harrison and Lindh's (1982) polar wander curve for North America, the inclination at Site 535 has changed little since Early Cretaceous. For the past $120 \mathrm{Ma}$, the calculated inclination at Site 

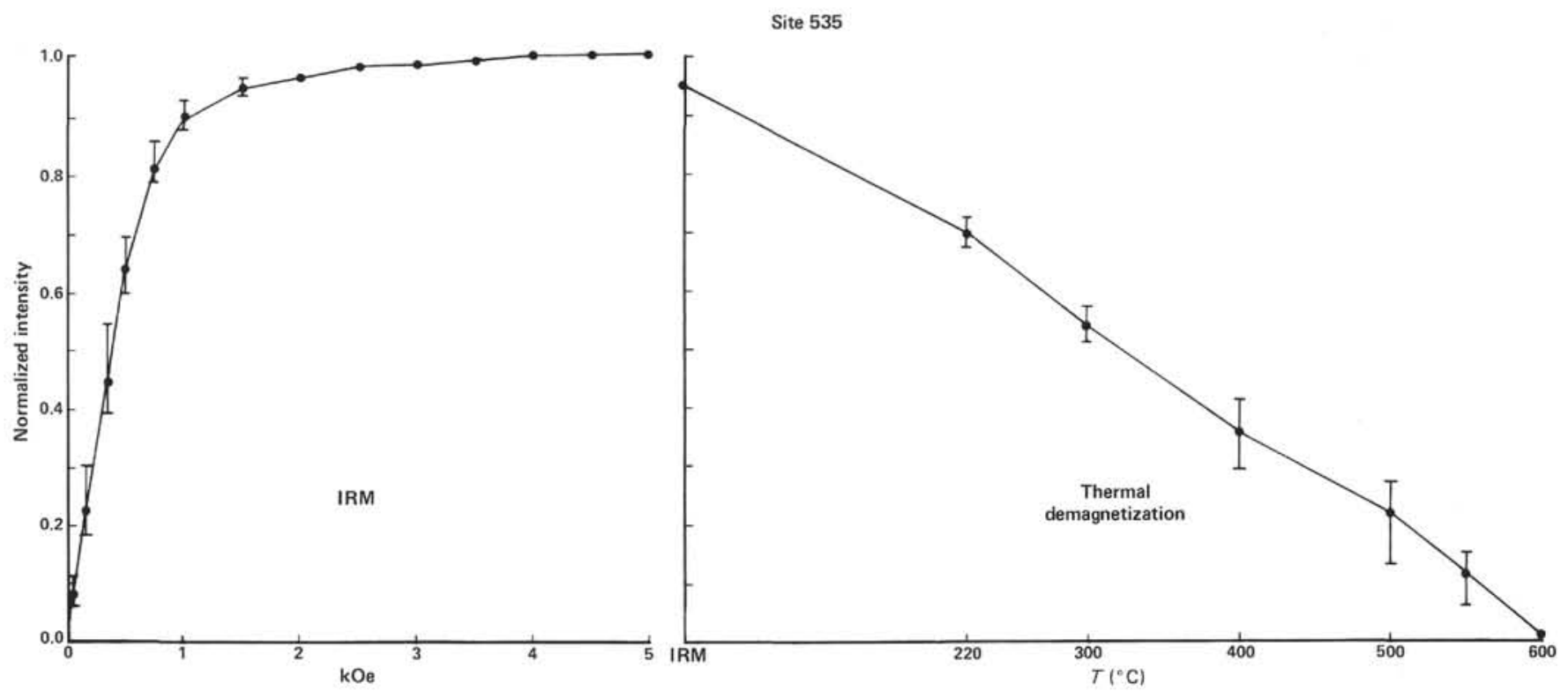

Figure 10. Change in normalized intensity during acquisition of an IRM and its removal by thermal demagnetization. Bars indicate range of normalized intensities for seven representative samples from Cores 39 through 56. Dots indicate average value.

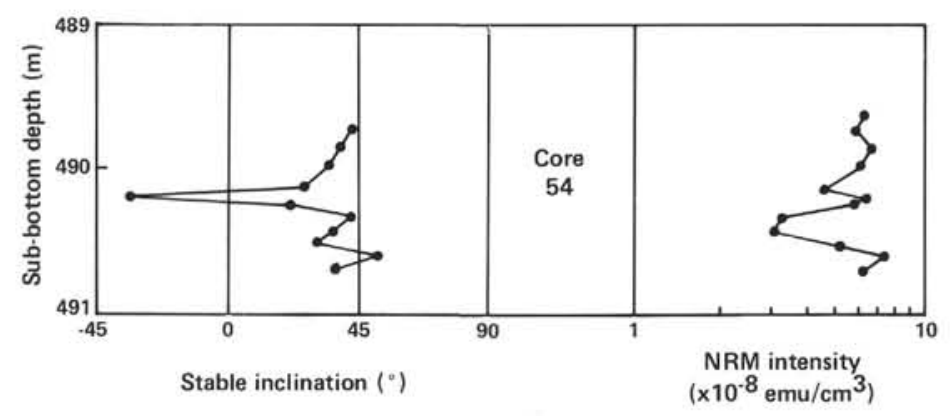

Figure 11. Stratigraphic plot of stable inclinations and NRM intensities for the reversely magnetized sample, 535-54-3, $20 \mathrm{~cm}$, and surrounding samples.

535 ranges from $35.5^{\circ}-43.6^{\circ}$, well within the error limits of the measured stable inclination of $37.8^{\circ} \pm 7.3^{\circ}$.

One possible scenario for remagnetization involves slumping and fluidization during a normal epoch. Above Core $43(400 \mathrm{~m})$ there is evidence of reworking, and possibly slumping. The microfossils are poorly zoned, and ammonites of considerably younger age (Cenomanian) than the microfossils are found. Because the fragile structures of the ammonites could not endure reworking, redeposition must have taken place during the Cenomanian (K. Young, 1981, pers. comm.). This is well within the Cretaceous long normal period, and if applicable to the whole measured section, could readily explain the paucity of reversed samples. However, the section below Core 43 shows no evidence of reworking; nannofossils are distinctly zoned in correct biostratigraphic succession (D. Watkins, 1981, pers. comm.). If slumping remagnetized this portion, the section must have moved as a unit but been sufficiently unconsolidated that fluidization during slumping allowed the magnetic grains to realign in the direction of the ambient field.
Thermal remagnetization is another possibility. This would involve heating the section above the blocking temperature of the magnetic grains for a sufficient length of time to reset the magnetism. Let us define remagnetization as heating a mineral to its Curie temperature $T_{\mathrm{c}}$ for $10 \mathrm{~min}$., i.e., $\tau_{T_{\mathrm{c}}}=600 \mathrm{~s}$. It is then possible to calculate the relaxation time $(\tau)$ at any other temperature $\left(\mathrm{T}_{2}\right)$ by transposing Néel's (1955) equation into

$$
T_{\mathrm{c}} \ln C \tau_{T \mathrm{c}}=T_{2} \ln C \tau_{T 2},
$$

where $C$ is a constant, $10^{9} \mathrm{~s}^{-1}$.

The temperature at Site 535 is constrained to a maximum of $60^{\circ} \mathrm{C}$ by the presence of immature organic matter (L. Magoon, 1981, pers. comm.) For magnetite, the relaxation time at $60^{\circ} \mathrm{C}\left(T_{2}\right)$ is 3680 b.y. Therefore, thermal demagnetization during a period of normal polarity is not a plausible explanation for these cores.

The third possible explanation for the exclusive presence of positive inclinations is that the paleontological 


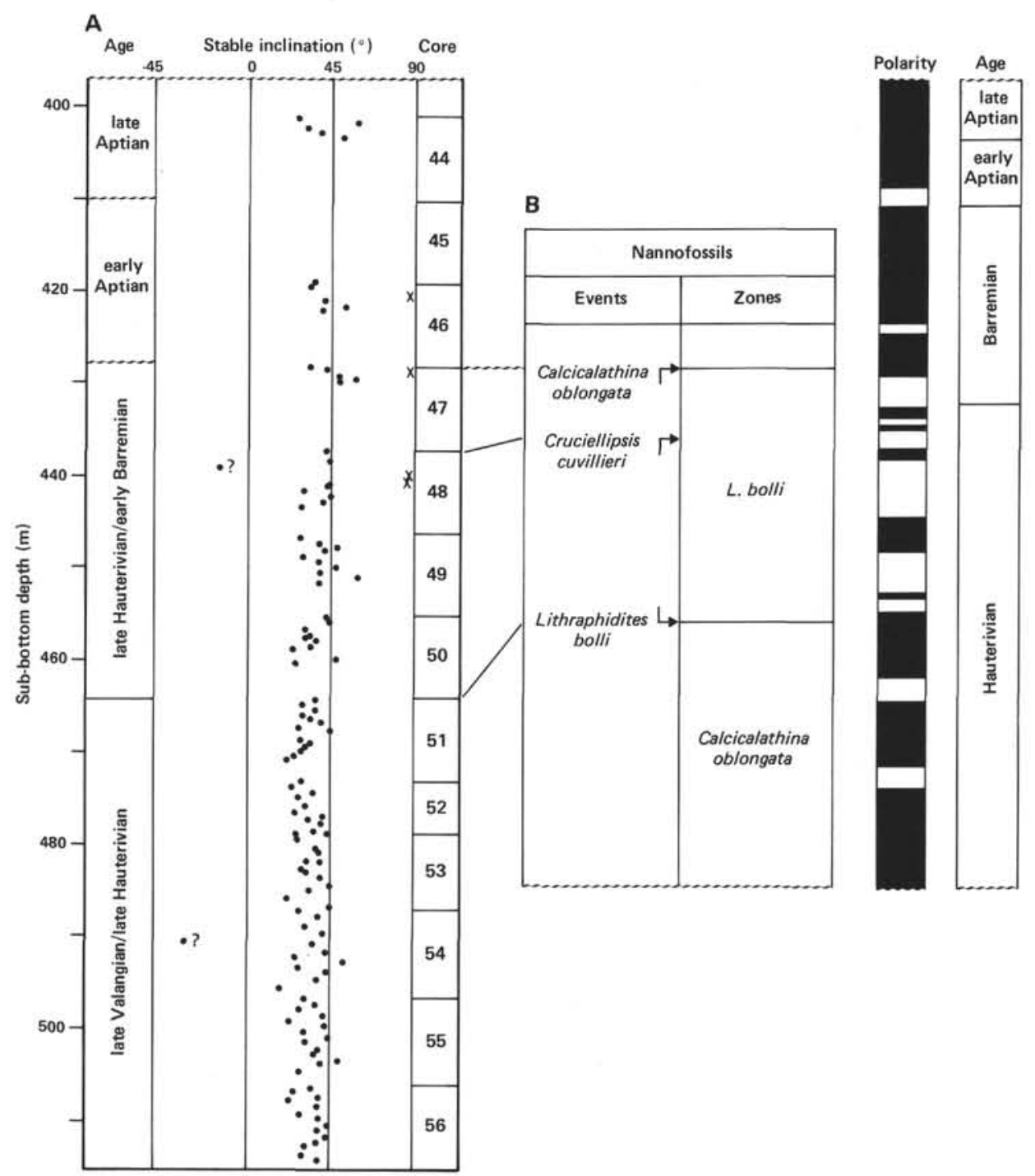

Figure 12. Comparison of results from Site 535 (A) with equivalent data from Italian limestones (B, modified from Channell et al., 1979). Black represents normal polarity; white, reverse polarity. X denotes samples which had no stable inclination, and ? indicates samples of questionable orientation.

dating is incorrect. Postcruise ammonite studies (Young, this volume) have revised the preliminary shipboard ages of Cores 18 through 43. However, in the lower section, where the reversals are expected, the nannofossil zonations are well defined and difficult to challenge. Ammonite dates from Cores 60 and 74 do suggest, however, that the microfossil dates may be systematically old. This is possible because the microfossil zones were defined by the first appearance of a species. If the first appearance of a species was delayed by environmental conditions, the age determination would be too old.

Young (this volume) has tentatively dated the ammonite piece from Core 60 as Late Hauterivian to Early Aptian. This would imply an even younger age for Core 56, which is the deepest core from which paleomagnetic samples were taken. An Early Aptian age would place Core 56 within the upper part of the $\mathrm{M}$ sequence, where reverse intervals are infrequent, and could easily go un- observed, depending on the deposition rate and sampling frequency.

\section{SUMMARY}

The lack of reversed zones in Cores $39-56$ is not compatible with the shipboard micropaleontological age assignment of Albian to Hauterivian. It suggests instead that the studied section is completely within the Cretaceous long normal zone (Santonian to Aptian). The discrepancy is possibly due to remagnetization during fluidization and slumping, but is most likely caused by the micropaleontological dates being too old. Postcruise ammonite work supports this contention.

\section{ACKNOWLEDGMENTS}

Special thanks go to David Watkins of Florida State University for doing the SEM work and attempting to resolve the discrepancy; to Dr. Keith Young of the University of Texas for fruitful discussions on his 
ammonite work and a preliminary copy of his manuscript; and to Dr. Wulf Gose for help in analyzing the data, preparing the figures, and revising the manuscript. This work was supported by the University of Texas at Austin. University of Texas Institute for Geophysics Contribution 568 .

\section{REFERENCES}

Channell, J. E. T., Lowrie, W., and Medizza, F., 1979. Middle and Early Cretaceous magnetic stratigraphy from the Cismon section, northern Italy. Earth Planet. Sci. Lett., 42:153-166.

Dunlop, D. J., 1973. Theory of the magnetic viscosity of lunar and terrestrial rocks. Rev. Geophys. Space Phys., 11:855-901.
Harrison, C. G. A., and Lindh, T., 1982. A polar wandering curve for North America during Mesozoic and Cenozoic. J. Geophy. Res., 87:1903-1920.

Lowrie, W., Channell, J. E. T., and Alvarez, W., 1980. A review of magnetic stratigraphy investigations in Cretaceous pelagic carbonate rocks. J. Geophy. Res., 85:3597-3605.

Néel, L., 1955. Some theoretical aspects of rock magnetism. Phil. Mag. Suppl. Adv. Phys., 4:191-243.

VandenBerg, J., and Wonders, A. A. H., 1980. Paleomagnetism of Late Mesozoic pelagic limestones from the Southern Alps. J. Geophys. Res., 85:3623-3627.

Date of Initial Receipt: February 11, 1983

Date of Acceptance: October 24, 1983 